\title{
Tubular Apocrine Adenoma - Case Report and Systematic Review
}

\author{
Mittal $\mathrm{S}^{1}$, Lynn $\mathrm{DC}^{1}$, Downing $\mathrm{KJ}^{2}$ and Plackett $\mathrm{TP}^{1^{*}}$ \\ ${ }^{1}$ Department of Surgery, Womack Army Medical Center, Fort Bragg, United States \\ ${ }^{2}$ Department of Pathology, Womack Army Medical Center, Fort Bragg, United States
}

${ }^{*}$ Corresponding author: Plackett TP, DO, FACS, MAJ, Department of Surgery, Womack Army Medical Center 2817 Reilly Road, Fort Bragg, NC 28307, Tel: (910) 907-6375, Fax: (910) 907-7935, E-mail: tplacke78@gmail.com

Citation: Mittal S, Lynn DC, Downing KJ, Plackett TP (2015) Tubular Apocrine Adenoma - Case Report and Systematic Review. SAJ Cas Rep 2: 203. doi: 10.18875/2375-7043.1.403

Article history: Received: 06 February 2015, Accepted: 12 May 2015, Published: 14 May 2015

\section{Abstract}

Tubular apocrine adenomas are relatively rare, benign, skin adnexal tumors with a limited number of cases reported in the literature. Herein is offered an additional case, as well as a thorough review and analysis of all previously reported cases.

Keywords: Tubular apocrine adenoma; Nevus sebaceous; Syringocystadenoma papilliferum

\section{Introduction}

There are many benign skin adnexal tumors with four main types of differentiation-apocrine, eccrine, follicular, and sebaceous [1]. A number of these tumors are very rare; amongst them is tubular apocrine adenoma (TAA), first described by Landry and Winkelmann in 1972 [2].

In their original description, Landry and Winkelmann used light microscopy, electron microscopy, and histochemistry to classify TAA. Some of the histologic findings that they described included numerous, well-defined lobules in the dermis, which were composed of variably sized tubules lined by two cell layers. The outer layer was cuboidal or flattend cells; the inner layer was columnar and exhibited decapitation secretion, as seen with apocrine sweat glands. The surrounding stroma was fibrous connective tissue with few plasma cells [2].

In addition to structure, Landry and Winkelmann used histochemistry to classify their patient's tumor. At that time, certain enzymes indicated eccrine or apocrine differentiation. Eccrine glandular tissues were positive for phosphorylase, whereas apocrine tissues were positive for acid phosphatase [2]. Later, investigators developed immunohistochemical methods to differentiated the two tissue types. In 1989, Ansai et al contributed to this diagnostic approach by identifying anti-CEA antigen and anti-S 100 protein as indicative of a TAA [10].

Since Landry and Winkelmann's initial description, greater than forty cases have been reported in the literature. We report another case of TAA appearing on the scalp of an elderly female. In addition to this case report, we completed a comprehensive review of other reported cases in an effort to summarize the characteristics of the tumor and help with future diagnoses.

\section{Case Report}

A 73 year-old African American woman presented with 2 non-painful, freely moveable lumps on her scalp. The lesions were circular in shape with regular boarders and measured $3 \mathrm{~mm}$ and $2 \mathrm{~mm}$ in size. The larger of the two masses was located near the apex of the scalp and had been slowly growing in size for the past year. The smaller mass was located near the occiput and had been present for only a couple of months. Even though they were not painful, she noticed them while combing her hair and requested their excision.

Both lesions were excised with a wide local excision. An oblong incision was made with 2 mm of clinically normal boarders along the narrowest portion. The incision was carried down to the hypodermis. Histologic analysis of the superior, larger lesion demonstrated a $6 \mathrm{~mm}$ papule with irregular tubular epithelial cells and stromal fibrosis (Figure 1). This was consistent with a tubular apocrine adenoma and the margins were involved with the tumor. The smaller lesion was found to be a $4 \mathrm{~mm}$ verruca vulgaris. No immunohistochemistry was performed on either lesion. 
A.

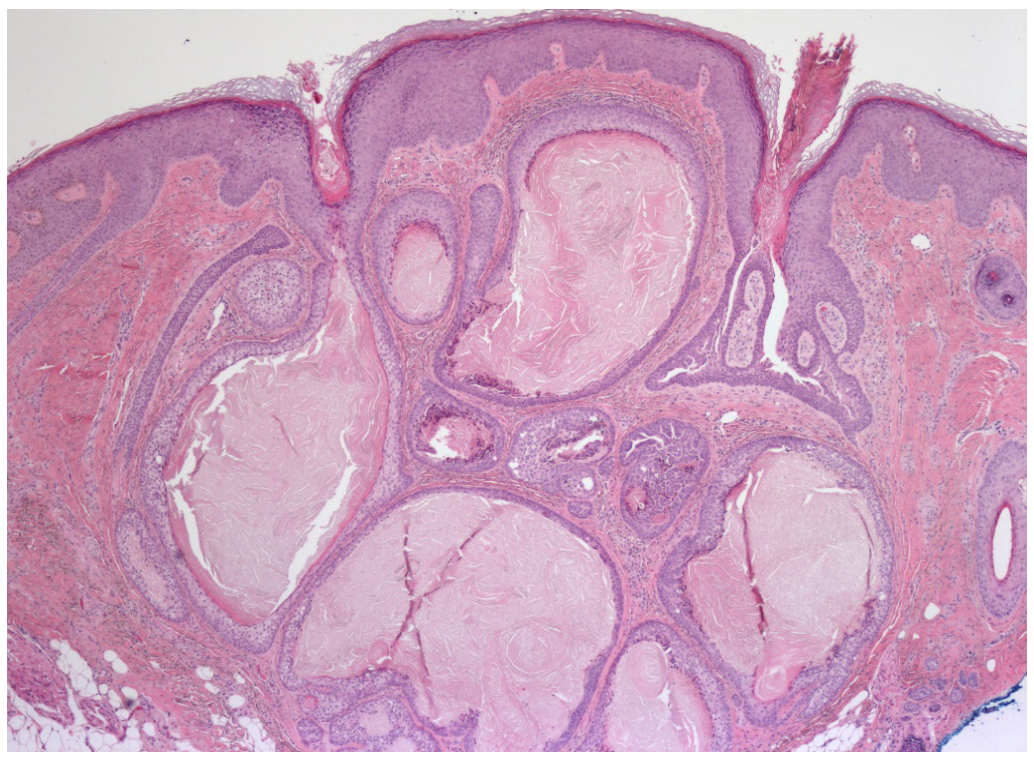

B.

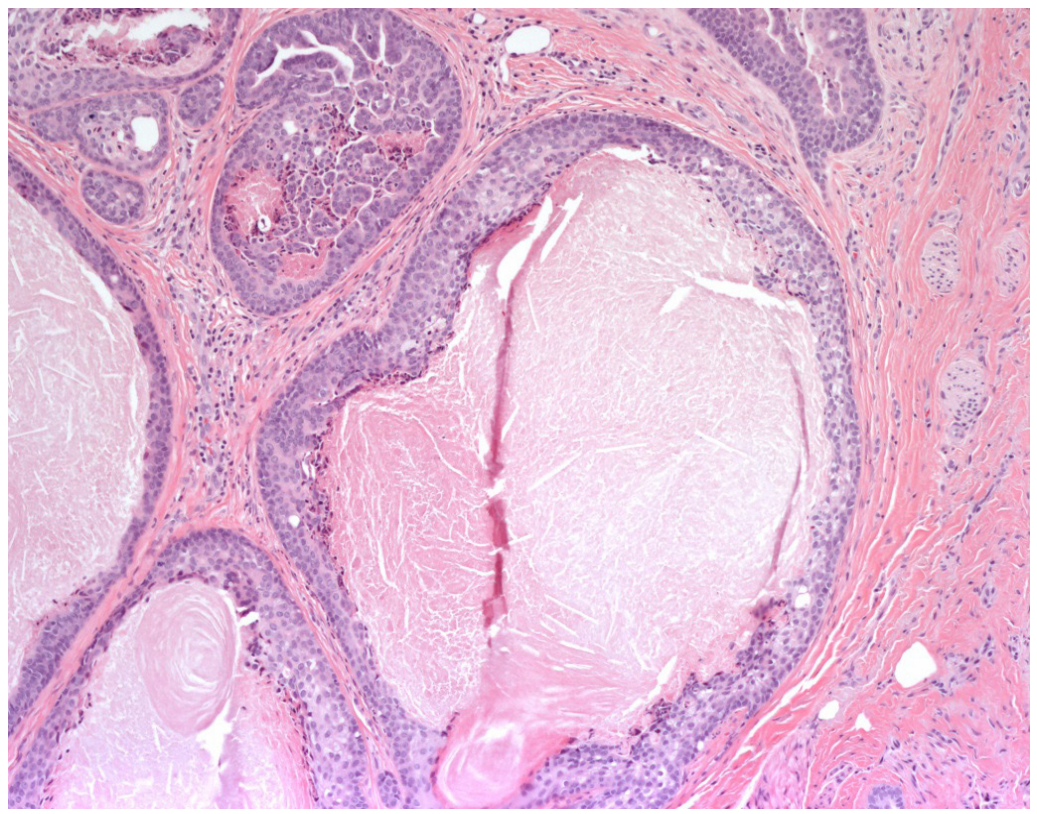

Figure 1: Histologic appearance. (A) Representative image of an H\&E stained slide at 4x demonstrating numerous well-differentiated, tubular structures arranged in a generally dermal-based, circumscribed growth pattern. Occasional comedo-like channels are present in connection with the epidermis. (B) Representative image of an H\&E stained slide at 10x demonstrating focal apocrine features with pseudo-papillae, luminal "decapitation" secretions, and abundant proteinaceous material.

The patient was seen in follow up and doing well. She was recommended to undergo repeat excision to obtain negative margins, but she has declined repeat excision and also elected to forgo clinical follow up.

\section{Methods}

A search of PubMed was performed on December 26, 2014 using the keywords "tubular apocrine adenoma" to identify reported cases of TAAs. The resultant manuscripts were reviewed by two authors (SM \& TPP) to assure appropriateness, and the references were reviewed to screen for additional case reports not previously identified. Demographics, accompanying pathology, and outcomes measures were abstracted from the manuscripts. Empty data sets were excluded from the analysis.

Summative data analysis was performed with the inclusion of the aforementioned case report included in the data set. Data are presented as mean \pm standard deviation. Categorical data are compared using a chi-square analysis and continuous outcomes are compared with a Student's t-test. A p-value of $<0.05$ was considered significant. All statistical analyses were performed using IBM SPSS Statistics, Version 22.

\section{Results}

Review of the literature identified 37 manuscripts describing 44 individual cases of TAAs, with the present case now accounting for a 45th patient (Table 1). All of the data points were not able to be abstracted from every case. 


\begin{tabular}{|c|c|c|c|c|}
\hline Manuscript & Age (years) & Sex & Lesion & Location \\
\hline Landry \& Winkelmann 1972 [2] & 66 & Female & TAA \& NS & Scalp \\
\hline Umbert \& Winkelmann 1976 [4] & 23 & Male & TAA \& NS & Scalp \\
\hline \multirow[t]{4}{*}{ Civatte et al 1979 [5] } & 44 & Female & TAA & Leg \\
\hline & 18 & Female & TAA & Scalp \\
\hline & 56 & Female & TAA & Leg \\
\hline & 76 & Female & TAA \& SCAP & Back \\
\hline Okun et al [6] & 57 & Female & TAA & Scalp \\
\hline Pippione \& Aloi 1983 [7] & 38 & Male & TAA & Back \\
\hline Burket \& Zelickson 1984 [8] & 69 & Female & TAA & Scalp \\
\hline Kanitakis et al 1984 [9] & 18 & Female & TAA & Back \\
\hline Toribio et al 1987 [10] & 33 & Female & TAA \& SCAP & Scalp \\
\hline Ansai et al 1989 [3] & 22 & Male & TAA \& SCAP & Scalp \\
\hline Yasuhara 1989 [11] & 34 & Female & TAA, NS, \& SCAP & Chest \\
\hline Ohtsuki et al 1990 [12] & 38 & Male & TAA & Abdomen \\
\hline \multirow[t]{4}{*}{ Barnadas et al [13] } & 67 & Female & TAA & Face \\
\hline & 71 & Female & TAA & Scalp \\
\hline & 32 & Female & TAA & Scalp \\
\hline & 78 & Female & TAA & Scalp \\
\hline Epstein et al 1990 [14] & 12 & Male & TAA \& SCAP & Chest \\
\hline Konohana et al 1991 [15] & 49 & Female & TAA & Genitalia \\
\hline Fox \& Cotton 1992 [16] & 26 & Female & TAA & Axilla \\
\hline Ishiko et al 1993 [17] & 75 & Male & TAA, NS, \& SCAP & Scalp \\
\hline Tellechea et al 1995 [18] & 19 & Female & TAA & Scalp \\
\hline Amo \& Kawano 2003 [19] & 62 & Male & TAA & Axilla \\
\hline Aktepe et al 2003 [20] & 19 & Male & TAA \& SCAP & Scalp \\
\hline Ahn et al 2004 [21] & 52 & Male & TAA, NS, \& SCAP & Scalp \\
\hline Stokes et al 2005 [22] & 63 & Female & TAA & Face \\
\hline Lee et al 2005 [23] & 74 & Female & TAA \& SCAP & Ear \\
\hline \multirow[t]{2}{*}{ Kazakov et al 2006 [24] } & 60 & Female & TAA & Scalp \\
\hline & 48 & Female & TAA & Back \\
\hline Martinelli et al 2006 [25] & 74 & Male & TAA & Face \\
\hline Yamane et al 2007 [26] & 77 & Female & TAA, NS, \& SCAP & Breast \\
\hline Vazmitel et al [27] & 61 & Male & TAA, NS, \& SCAP & Scalp \\
\hline El Demellaway et al [28] & 58 & Female & TAA & Genitalia \\
\hline Goodden et al 2008 [29] & 6 days & Female & TAA \& SCAP & Scalp \\
\hline Ross \& Shwayder 2010 [30] & 8 & Female & TAA & Genitalia \\
\hline Kim et al $2010[31]$ & 40 & Female & TAA, NS, \& SCAP & Scalp \\
\hline Mitsuishi \& Kawana 2011 [32] & 61 & Female & TAA & Face \\
\hline Lee et al $2011[33]$ & 12 & Male & TAA \& SCAP & Abdomen \\
\hline Nakagomi et al 2011 [34] & 64 & Male & TAA & Abdomen \\
\hline Yoon et al 2011 [35] & 59 & Male & TAA \& SCAP & Leg \\
\hline Gozel et al 2013 [36] & 70 & Female & TAA, NS, \& SCAP & Scalp \\
\hline Baker et al 2013 [37] & 60 & Female & TAA & Genitalia \\
\hline Ito et al 2014 [38] & 63 & Male & TAA & Face \\
\hline
\end{tabular}

Table 1: Described cases of tubular apocrine adenomas

The mean patient age at diagnosis was $48.9 \pm 22.1$ years with a trend toward increased incidence in the latter decades of life (Figure 2). However, it should be noted that several patients had a history of waiting multiple years to have the mass excised, and therefore the onset may be younger than the current data suggests. In fact, nine patients (20\%) the lesions excised were reported to have been present since birth. The majority of patients (64\%) were females. These findings of a predominance of tubular apocrine adenomas 
occurring in middle-aged females is in keeping with what other have reported [28,29,33].

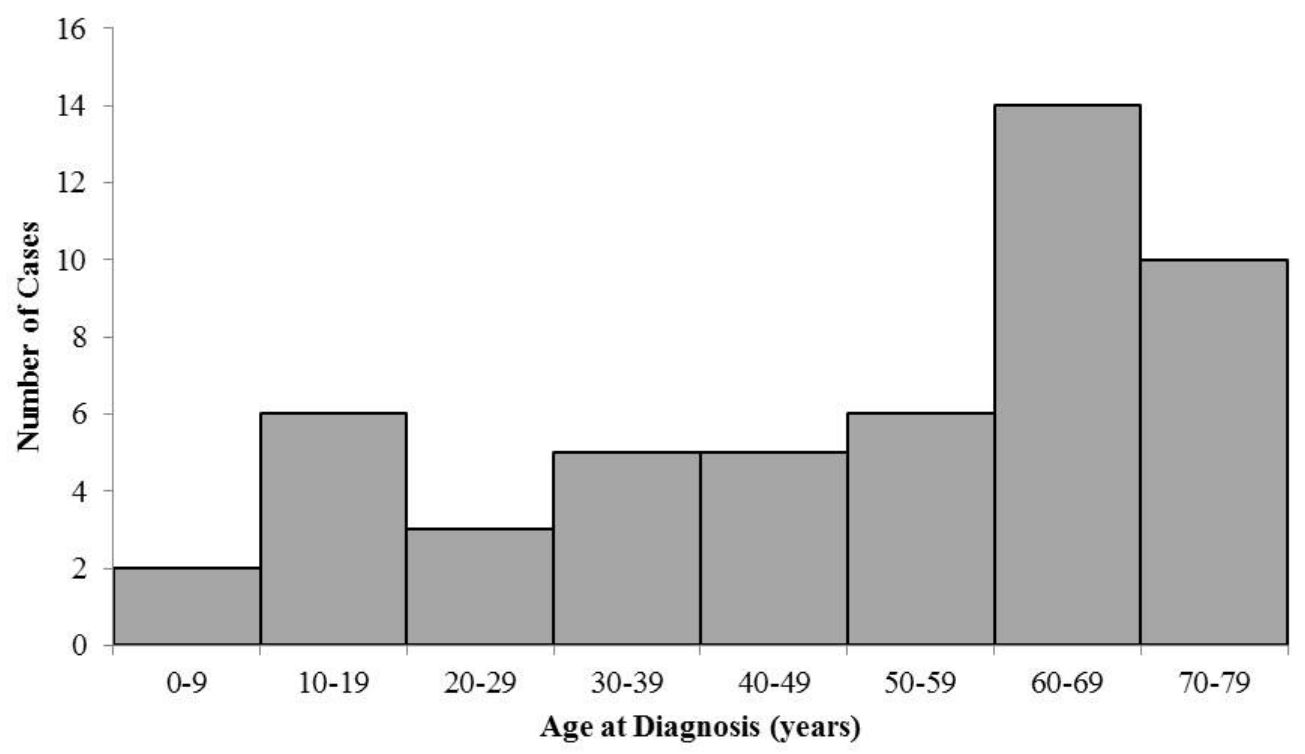

Figure 2: Patient age at diagnosis

Tubular apocrine adenomas have been described as occurring on a variety of areas across the body (Figure 3), however the majority of cases occur on the scalp and over half of them occur above the level of the shoulders. Other less commonly reported body areas include the chest (including axilla and breast), back, lower extremity, genitals, and abdomen. As tubular apocrine adenomas are a benign skin adnexal tumor with apocrine gland differentiation, this body distribution is surprising since apocrine skin glands typically have a very limited distribution in the body, being found usually in the axilla and anogenital regions [39].

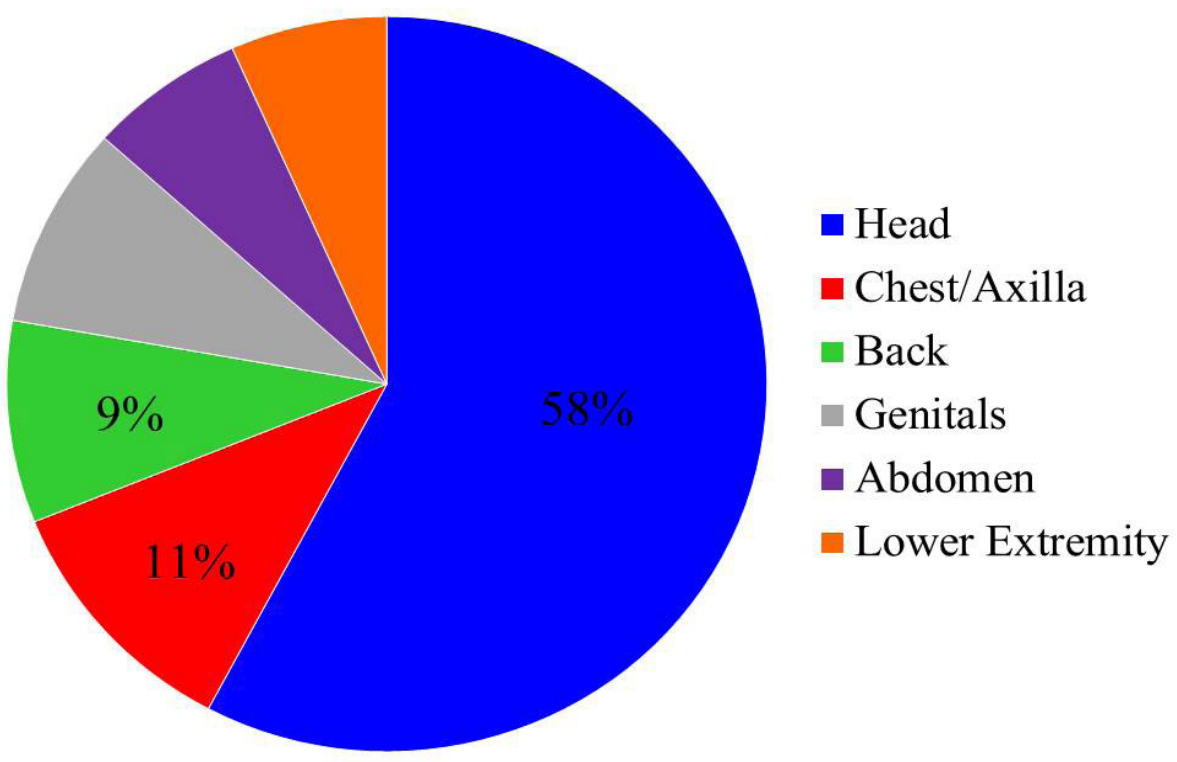

Figure 3: Involved region of the body

Theories regarding the origin of the tumor have been developed [11]. These types of tumors may develop from primary epithelial germ cells, pluripotent cells, or cells of pre-existing structures. Based on the distribution seen in Figure 3, it seems unlikely that these TAAs could be derived from cells of pre-existing structures, because, as mentioned, apocrine glands are considered normal adnexa of the axilla and anogenital regions, not the head. Therefore, these benign skin tumors are likely derived from primary epithelial germ cells or pluripotent cells.

Tubular apocrine adeonomas are commonly found with other dermatologic neoplasms. In $40 \%$ of cases, the patient also had a nevus sebaceous/organoid Nevus of Jahassohn (NS) and/or syringocystadenoma papilliferum (SCAP). The presence of multiple benign adnexal tumors in the same specimen has led to some controversy regarding the classification and relationship of these tumors to each other. This controversy emerged shortly after Landry and Winkelmann's first description of tubular apocrine adenomas [2] when Fisher argued that TAAs were merely a variant of SCAP [40]. However, subsequent studies using light microscopy, electron 
microscopy, and immunohistochemical analysis have shown that these are related, but distinctly separate tumors [17]. Findings that are more suggestive of a TAA include a predominantly tubular pattern to the epithelial layer, stromal fibrosis, and the presence of comedo-like structures, whereas findings more suggestive of SCAP include cystic dilation of the epithelial tubules, plasma cells in the stroma, papillomatosis, and cystic invagination of the surface of the skin [14].

It has been proposed that much of the difficulty in differentiating between these tumors may be due to the potential for TAAs to develop from SCAP and/or NS [31]. Apocrine glands have been noted to be present deep within NS, and these glands may be the origin of TAAs that develop later in life [21]. Further supporting this assertion are the observations that all cases of TAAs occurring with NS and/or SCAP occur in lesions present for over 5 years prior to excision, and that the majority of lesions had been present since birth or childhood. These findings suggest that these tumors arise from either pluripotent or primary epithelial germ cells.

Despite the similarities between these tumors, minor differences exist in the epidemiology of these conditions as summarized in Table 2. Patients with concomitant TAAs and SCAP are diagnosed at a similar age, but are more likely to have been reported to occur in a lesion present since birth or childhood than patients with isolated TAAs. Also, the female predominance is lost in the setting of concomitant disease. The distribution of involved body parts is essentially unchanged between the two groups. While none of these differences reach statistical significance, the limited number of reported cases does allow for a potential type II error.

\begin{tabular}{|c|c|c|c|}
\hline Demographic & TAA (n=30) & TAA with SCAP (n=16) & p value \\
\hline Age at diagnosis (years) & $49.6 \pm 19.4$ & $44.8 \pm 25.7$ & 0.490 \\
\hline Male, No (\%) & $9(30)$ & $8(50)$ & 0.177 \\
\hline $\begin{array}{c}\text { Lesion since birth or childhood, No. } \\
\text { (\%) }\end{array}$ & $4(13)$ & $11(69)$ & $<0.001$ \\
\hline Located on the head, No. (\%) & $17(57)$ & $9(56)$ & 0.978 \\
\hline
\end{tabular}

Table 2: Comparison of epidemiology of isolated tubular apocrine adenoma versus tubular (TAA) apocrine adenoma with syringocystadenoma papilliferum (SCAP)

Since Landry and Winkelmann's original case, the treatment of tubular apocrine adenoma has consistently been excision of the lesion to negative margins. This recommendation has been reinforced by Burkett \& Zelickson, who presented a case of tubular apocrine adenoma that showed perineural invasion [8]. In light of this case, many authors have recommended excision of the lesion with wide margins. Excision or re-excision (if necessary) has been curative according to all case reports, although long term follow up is limited.

\section{Conclusion}

Tubular apocrine adenomas are an infrequently reported skin adnexal tumors with less than 50 reported cases in the literature. It typically forms on the head, specifically the scalp, but has been reported in multiple areas throughout the body. The tumor is more common in males and is generally diagnosed during adulthood. However, the age of onset of the lesion is more difficult to ascertain as there are numerous reports of these lesions having been present since childhood. While this tumor has been associated with other benign skin adnexal tumors, making diagnosis difficult, it remains a distinct entity. The management of this tumor has not changed since its first description in 1972 [2]; the curative treatment remains excision. The relatively limited number of reported cases has hindered a thorough understanding of this tumor and its natural history. However, this remains a clinical entity that the practitioner should be aware of and consider within their differential diagnosis as there is some concern for malignant degeneration and/or perineural invasion.

\section{Acknowledgment}

The views expressed herein are those of the authors and do not reflect the official policy of the Department of the Army, Department of Defense, or the U.S. Government

\section{References}

1. Klein W, Chain E, Sykora JT (2005) Tumors of the Epidermal Appendages. Levers' Histopathology of the Skin (9th Edition) Philadelphia: Lippincott Williams and Wilkins 867-906.

2. Landry M, Winkelmann RK (1972) An unusual tubular apocrine adenoma. Arch Dematol 105: 869-79.

3. Ansai S, Watanabe S, Aso K (1989) A case of tubular apocrine adenoma with syringocystadenoma papilliferum. J Cutan Pathol 16: 230-6.

4. Umbert P, Winkelmann RK (1976) Tubular apocrine adenoma. J Cutan Pathol 3: 75-87.

5. Civatte J, Belaich S, Lauret P (1979) Tubular apocrine adenoma (4 cases). Ann Dermatol Venereol 106: 665-9.

6. Okun MR, Finn R, Blumental G (1980) Apocrine adenoma versus apocrine carcinoma. Report of two cases. J Am Acad Dermatol 2: $322-6$.

7. Pippione M, Aloi FG (1983) Apocrine tubular adenoma. G Ital Dermatol Venereol 118: 327-30.

8. Burket JM, Zewlickson AS (1984) Tubular apocrine adenoma with perineural invasion. J Am Acad Dermatol 11: 639-42.

9. Kanitakis J, Hermier C, Thivolet J (1984) Tubular apocrine adenoma: apropos of a case. Dermatologica 169: 23-8. 
10. Toribio J, Zulaica A, Peteiro C (1987) Tubular apocrine adenoma. J Cutan Pathol 14: 114-7.

11. Yasuhara M (1989) Typical but rare cases. Tokyo: Seishindou. 1989.

12. Ohtsuki M, Kobayashi Y, Kawaguchi S, Hino H (1990) A case of tubular apocrine adenoma. Rinshouhifuka 44: 1063-7.

13. Barnadas MA, Moreno A, Rujol R, Freeman RG, De Moragas JM (1990) Tubular apocrine adenoma. Description of 4 cases. Med Cutan Ibero Lat Am 18: 35-9.

14. Epstein BA, Argenyi ZB, Goldstein G, Whitaker D (1990) An unusual presentation of a congenital benign apocrine hamartoma. J Cutan Pathol 17: 53-8.

15. Konohana I, Niizeki H, Ikutomi M (1991) A case of tubular apocrine adenoma located on the genital area. Rinshouhifuka 45: 809-12.

16. Fox SB, Cotton DW (1992) Tubular apocrine adenoma and papillary eccrine adenoma. Entities or unity? Am J Dermatopathol 14: 149-54.

17. Ishiko A, Shimizu H, Inamoto N, Nakmura K (1993) Is tubular apocrine adenoma a distinct clinical entity? Am J Dermatopathol 15: 482-7.

18. Tellechea O, Reis JP, Marques C, Baptista AP (1995) Tubular apocrine adenoma with eccrine and apocrine immunophenotypes or papillary tubular adenoma? Am J Dermatopathol 17: 499-505.

19. Amo Y, Kawano N (2003) A case of ductal apocrine carcinoma in the left axilla with tubular apocrine adenoma in the right axilla. J Dermatol 30: $72-5$.

20. Aktepe F, Demir Y, Dilek FH (2003) Tubular apocrine adenoma in association with syringocystadenoma papilliferum. Dermatol Online J 9: 7.

21. Ahn BK, Park YK, Kim YC (2004) A case of tubular apocrine adenoma with syringocystadenoma papilliferum arising in nevus sebaceous. J Dermatol 31: 50810.

22. Stokes J, Ironside J, Smith C, Dhillon B (2005) Tubular apocrine adenoma -an unusual eyelid tumor. Eye 19: 237-9.

23. Lee CK, Jang KT, Cho YS (2005) Tubular apocrine adenoma with syringocystadenoma papilliferum arising from the external auditory canal. J Laryngol Otol 119: 1004-6.

24. Kazakov DV, Mukensnabl P, Michal M (2006) Tubular adenoma of skin with follicular and sebaceous differentiation: a report of two cases. Am J Dermatopathol 28: $142-6$.

25. Martinelli PT, Cohen PR, Schulze KE, Tschen JA, Nelson BR (2006) Mohs micrographic surgery for tubular apocrine adenoma. Int J Dermatol 45: 1377-8.

26. Yamane N, Kato N, Yanagi T, Osawa R (2007) Naevus sebaceous on the female breast accompanied with a tubular apocrine adenoma and a syringocystadenoma papilliferum. Br J Dermatol 156: 1397-9.

27. Vazmitel M, Michal M, Mukensnabl P, Kazakov DV (2008) Syringocystadenoma papilliferum with sebaceous differentiation in an interadermal tubular apocrine component. Report of a case. Am J Dermatopathol 30: 51-3.

28. El Demellawy D, Daya D, Alowami S (2008) Vulvar apocrine tubular adenoma: an unusual location. Int J Gynecol Pathol 27: 301-3.

29. Goodden JR, Marven SS, Cohen M, de Ville McMullan PJ, Smith MF (2008) Congenital apocrinetumour: a rare scalp tumour. Eur J Ped Surg 18: $282-4$.

30. Ross I, Shwayder T (2010) Tubular apocrine adenoma: presentation in the vaginal introitus of an eight-year-old. Pediatr Dermatol 27: 200-1.

31. Kim MS, Lee JH, Lee WM, Son SJ (2010) A case of tubular apocrine adenoma with syringocystadenoma papilliferum that developed in a nevus sebaceous. Ann Dermatol 22: 319-22.

32. Mitsuishi T, Kawana S (2011) Tubular apocrine adenoma of the nose. Eur J Dermatol 21: 132.

33. Lee HJ, Cho E, Kim MH, Cho SH, Lee JD (2011) Syringocystadenomapapilliferum of the back combined with a tubular apocrine adenoma. Ann Dermatol 23: S151-4.

34. Nakagomi D, Harada K, Shimada S (2012) Case of tubular apocrine adenoma with follicular differentiation location on the trunk. J Dermatol 39: 653-4.

35. Yoon JH, Ahn HH, Kye YC, Seo SH (2011) Syringocystadenoma papilliferum in co-existence with tubular apocrine adenoma on the calf. Ann Dermatol 23: S175-8.

36. Gozel S, Donmez M, Akdur NC, Yikilan H (2013) Development of six tumors in a sebaceous nevus of Jadassohn: report of a case. Korean J Pathol 47: 569-74.

37. Baker GM, Selim A, Hoang MP (2013) Vulvar adnexal lesions: a 32-year, single-institution review from Massachusetts General Hospital. Arch Pathol Lab Med 137: 1237-46.

38. Ito T, Nomura T, Fujita Y, Abe R, Shimizu H (2014) Tubular apocrine adenoma clinically and dermoscopically mimicking basal cell carcinoma. J Am Acad Dematol 71: e45-6.

39. Murphy GF, Elder DE (1990) Atlas of tumor pathology: non-melanocytic tumors of the skin. Armed Forces Institute of Pathology 3rd Series. Washington, DC,USA, 61-127.

40. Fisher TL (1973) Tubular apocrine adenoma. Arch Dermatol 107: 37. 